\title{
Sick leave and work disability in patients with early arthritis
}

\author{
Elisabeth J. M. Zirkzee • Arina C. Sneep • \\ Petronella D. M. de Buck • Cornelia F. Allaart • \\ Andreas J. Peeters • H. Karel Ronday • Marie Louise Westedt • \\ Saskia le Cessie • Theodora P. M. Vliet Vlieland
}

Received: 18 December 2006/Revised: 19 April 2007 / Accepted: 21 April 2007 / Published online: 10 May 2007

(C) Clinical Rheumatology 2007

\begin{abstract}
We studied the occurrence of sick leave and work disability, the presence of workplace adaptations and the usage of professional guidance related to working problems in patients with early arthritis. Inclusion criteria were arthritis symptoms of less than 2 years duration and a paid job at the time of diagnosis. Assessments were done in connection with an early arthritis clinic (EAC) at entry into the cohort and 12 months thereafter by means of a questionnaire comprising questions on sick leave (absenteeism from work
\end{abstract}

\author{
E. J. M. Zirkzee - A. C. Sneep · P. D. M. de Buck - C. F. Allaart \\ T. P. M. Vliet Vlieland $(\triangle)$ \\ Department of Rheumatology C1-R, \\ Leiden University Medical Center, \\ P.O. Box 9600, 2300 RC Leiden, The Netherlands \\ e-mail: t.p.m.vliet_vlieland@lumc.nl \\ P. D. M. de Buck \\ Department of Medical Decision Making, \\ Leiden University Medical Center, \\ Leiden, The Netherlands
}

\section{A. J. Peeters}

Department of Rheumatology, Reinier de Graaf Gasthuis,

Delft, The Netherlands

H. K. Ronday

Department of Rheumatology,

Haga-Leyenburg Teaching Hospital,

The Hague, The Netherlands

\section{L. Westedt}

Department of Rheumatology, Bronovo Hospital,

The Hague, The Netherlands

\section{S. le Cessie}

Department of Medical Statistics,

Leiden University Medical Center,

Leiden, The Netherlands reported to the employer), work disability (receiving a full or partial work disability pension), unemployment, work adaptations and professional guidance related to working problems. Fifty-seven of the 69 participants $(83 \%)$ had an arthritis symptom duration of $<6$ months. The number of patients with sick leave due to arthritis in the past 12 months decreased from $28(41 \%)$ at study entry to $18(26 \%)$ after 12 months of follow-up. The number of patients receiving a work disability pension increased from $5(7 \%)$ at study entry to $13(19 \%)$ after 12 months of follow-up (10 partial and 3 full). Sick leave in the 12 months before study entry appeared to be the most important predictor of the institution or increase in a work disability pension (odds ratio, 16.1; 95\%CI, 1.8-142.8). Between study entry and follow-up, the number of patients with workplace adaptations increased from $20(29 \%)$ to $28(42 \%)$, whereas the number of patients receiving vocational guidance decreased from $48(70 \%)$ to $36(52 \%)$. In patients with early arthritis and a paid job, arthritis-related sick leave was common and occurred in part before patients entered the EAC and a diagnosis was made. About $20 \%$ of the patients became permanently work disabled, with partial work disability being more common than full work disability. Considerable proportions of patients received workplace adaptations and professional guidance with working problems.

Keywords Arthritis - Occupational health - Sick leave · Vocational rehabilitation $\cdot$ Work disability

\section{Introduction}

Rheumatoid arthritis (RA) and other chronic inflammatory rheumatic diseases are disabling conditions that affect the 
lives of individual patients in many ways. The prevalence of work disability is high among patients with RA [1], as well as other forms of chronic arthritis, such as ankylosing spondylitis [2], systemic lupus erythematosus [3] and to a lesser extent psoriatic arthritis [4, 5]. In RA patients, it was found that most work disability develops rapidly after onset [6], with recent studies showing work disability rates among RA patients 1 year after diagnosis vary between 15 and $30 \%$ [7-9].

So far, research has focussed mainly on permanent work disability and its determinants [10]. Over the recent years, the interest in sick leave, which is considered to precede permanent work disability in chronic arthritis, is increasing. In cross-sectional studies in early RA (disease duration $<2$ years), the proportions of patients on sick leave varied from $5-55 \%$ [7, 11-13], whereas in follow-up studies, $50-60 \%$ of the patients reported sick leave over a period of 1 year $[7,14,15]$.

Until now, the number of studies on work disability and sick leave in early arthritis is confined to the situation after diagnosis, with no data being available on the occurrence of sick leave or permanent work disability in the preceding period. In addition, little is known about the extent of adaptations to the work place or guidance by health professionals in these early stages of the disease.

The aim of this study was therefore to describe the occurrence of sick leave and permanent work disability and its predictors in the very early phases of the disease. Moreover, this study aimed to describe the provision of adaptations to the workplace and professional guidance in patients with chronic arthritis.

\section{Materials and methods}

\section{Patients}

This work disability study was originally designed as a multicenter study, including the Leiden University Medical Center (LUMC) Leiden, the Haga-Leyenburg Teaching Hospital and Bronovo Hospital, The Hague and the Reinier de Graaf Hospital, Delft, The Netherlands. We aimed to recruit patients in connection with two cohorts, the early arthritis clinic [16] (EAC; LUMC patients only) and the BeSt study [17] (LUMC, Haga-Leyenburg Teaching Hospital, Bronovo Hospital and Reinier de Graaf Gasthuis). BeSt is an abbreviation of treatment strategies (in Dutch: BehandelStrategieën) for RA, with four drug treatment strategies all aimed at achieving low disease activity being compared in patients with early, active RA [17]. The Medical Ethics Committees of all three participating hospitals approved the protocol of this additional work disability study.
Due to logistical problems, the actual recruitment of patients in the period 2000-2003 has only been carried out in connection with the EAC in the LUMC. The EAC is a facility aimed at early diagnosis and treatment of arthritis, including all patients suffering from arthritis in one or more joints, an arthritis symptom duration of less than 2 years, and not being diagnosed with gout, chondrocalcinosis or traumatic arthritis or a serious disease other than a rheumatic condition. General practitioners are requested to refer patients with suspected arthritis as soon as possible; all patients can be seen within 2 weeks after referral [16]. Only patients who had a paid job 12 months before the first visit in connection with the EAC were included.

On average, a definite diagnosis was made within 2 weeks after the first visit in connection with the EAC. At the time the present study was conducted, patients who were diagnosed with RA were promptly treated with either methotrexate or salazopyrine. RA patients fulfilling the inclusion criteria for the BeSt study [RA according to the American College of Rheumatology, formerly American Rheumatism Association, criteria [18], a disease duration of less than 2 years, aged 18 years or older and active disease indicated by $\geq 6$ of 66 swollen joints, $\geq 6$ of 68 tender joints and at least one of the following two criteria: an erythrocyte sedimentation rate (ESR) of $\geq 28 \mathrm{~mm} / \mathrm{h}$ or a global health score of $\geq 20 \mathrm{~mm}$ on a $0-100 \mathrm{~mm}$ visual analogue scale (VAS), where $0=$ best and $100=$ worst] were randomized to four treatment groups. These groups included sequential monotherapy (group 1), step-up combination therapy (group 2), initial combination therapy with tapered highdose prednisone (group 3), or initial combination therapy with infliximab (group 4). For patients failing on their medication, the study protocol prescribed a number of subsequent treatment steps [17].

All patients included in the work disability study gave written informed consent.

\section{Assessment methods}

Assessments were done at study entry (at study inclusion of the EAC cohort) and after 12 months of follow-up. Basic sociodemographic and clinical data were obtained from the baseline assessments of the EAC, whereas data on the working situation and mental health were gathered by means of additional questionnaires.

\section{Sociodemographic and clinical characteristics}

Sociodemographic variables included age, sex, status of living (living with a partner yes/no) and education level, divided into three categories: primary education ( $0-8$ years), secondary education (9-16 years) and higher vocational education /university (17 years or more). 
Disease activity was measured by means of (a) the ESR $(\mathrm{mm} / \mathrm{h})$; (b) the Ritchie score, concerning pain in 26 selected joints on a scale of $0-3(0=$ no pain and $3=$ worst pain), with the final score ranging from 0-69 [19] and (c) the patient's global assessment of disease activity, pain and fatigue on three separate VAS. All VAS were $10 \mathrm{~cm}$ horizontal lines, with the anchors on the left being no disease activity, no pain and no fatigue, whereas the anchors on the right were the worst imaginable disease activity, severe pain and severe fatigue.

Physical functioning was measured by the Health Assessment Questionnaire (HAQ). The HAQ is a 20-item questionnaire comprising eight domains of activities of daily living, with the final score ranging from 0 (no disability) to 3 (severe disability) [20].

Anxiety and depression were measured by means of a Dutch version of the Hospital Anxiety and Depression Scale (HADS) [21]. The higher the scores on the anxiety or depression scales the more anxious or depressed the subject is (range, $0-21$ per scale).

\section{Job characteristics, sick leave, work disability, work adaptations and guidance with working problems}

Current occupation was grouped into four categories: (1) predominantly mental demands and absence of physical demands, (2) a combination of physical and mental effort, (3) light physical demands and (4) heavy physical demands [22].

Sick leave was defined as absenteeism with a duration of 2 weeks or more, related to the arthritic complaints and reported to the employer. At the time the study was conducted, in the Dutch social security regulations, the maximum duration of sick leave was 1 year, and sick leave could be either complete (reported sick for all hours that one is engaged) or partial (reported sick for part of the hours that one is engaged). The duration of sick leave in the 12 months before study entry and 1 year thereafter was divided into four categories: (1) 2-4 weeks, (2) 1-3 months, (3) 3-6 months, (4) 6-9 months and (5) 9-12 months.

Permanent work disability was defined as receiving a complete or partial work disability pension related to the rheumatic disease. In the Dutch social security regulations, a partial work disability pension in combination with a parttime job is common. In this situation, sick leave may occur during the hours active at work.

The presence of material or immaterial adaptations at the workplace (including adapted tools, adapted furniture, reduction in tasks or duties, help of colleagues, flexible working hours, opportunities for more breaks, less working hours or reduced work pace) was recorded. Reduced working hours were only considered as an adaptation at work when this adaptation did not pertain to official, incomplete sick leave.
Guidance with working problems was recorded by means of a question concerning the receipt of help in maintaining the job. Health professionals listed for giving help were: the rheumatologist, occupational physician, general practitioner, social worker, physical therapist, occupational therapist or nurse. In addition, it was registered whether patients received support from their employer and/or colleagues. Satisfaction with the received guidance was recorded. In addition, patients were asked by whom they would have liked to be helped more.

Background information on sick leave and work disability

Background information on sick leave and work disability in the Dutch population in the period the study was conducted was derived from the Internet site of the Dutch Central Bureau of Statistics, http://www.cbs.nl.

\section{Statistical analysis}

Data entry was performed using Microsoft Office Access 2000. Statistical analyses were executed using SPSS 10.0 for Windows.

Continuous variables were presented as medians with ranges and categorical variables as number and percentages. Comparisons of the median age and the sex distribution of patients included in the study and all other patients of 65 years or younger who entered the EAC cohort in the study period were done by means of the Mann-Whitney $U$ and chi-square test, respectively.

Proportions of patients being on sick leave or receiving a work disability pension at study entry and after 12 months of follow-up were compared using McNemar tests for paired comparisons of categorical data, whereas the average numbers of hours per week patients were working were compared by means of the Wilcoxon signed rank test. These analyses were repeated excluding all patients with a symptom duration $>6$ months at study entry.

Sociodemographic, disease and job characteristics in the group of patients in whom the working situation deteriorated after 12 months of follow-up (defined as being entitled a partial or full work disability pension for the first time or changing from a partial to a full work disability pension) and in the group of patients in whom the working situation remained stable or improved (defined as receiving no disability pension or the same partial work disability pension at either time point of changing from a partial work disability pension to no disability pension) were compared by Mann-Whitney $U$ and chi-square tests.

Then, a multivariate backward logistic regression analysis on predictors of deterioration of the working status was performed. Only variables that showed a significant difference in the above-mentioned analysis ( $p$ values $\leq 0.1$ ) were entered as independent variables in logistic regression analysis. 
The numbers of patients receiving adaptations in the workplace or vocational guidance in the past year at study entry and after 12 months of follow up were compared by the McNemar test, whereas the median total numbers of workplace adaptations per patient at both time points were compared by means of the Wilcoxon signed rank test.

\section{Results}

In the study period, in total, 418 patients entered the EAC cohort. One hundred and five of these 418 patients (25.1\%) were older than 65 years. From the remaining 313 patients, 81 patients $(25.9 \%)$ were found eligible and willing to participate. The reasons for not being included were not recorded on the individual level. A group of patients was not eligible for the study because they were not having a paid job 12 months before the first visit in connection with the EAC cohort. In addition, a number of patients were eligible but declined participation, and some patients were not invited because of logistic reasons.

Twelve of the initially included patients were excluded within 2 weeks after enrollment because a diagnosis of gout, chondrocalcinosis, sarcoidosis or a non-rheumatic disease was confirmed after additional diagnostic procedures so that they did not meet the inclusion criteria for the EAC.

The 69 patients included in the study were younger (median age, 42.0 years; range 18-64) than the 244 patients in the EAC cohort aged 65 years or less who were not included (median age, 48.0 years; range, $18-65$; $p=0.08$ ). Moreover, the proportion of female patients was lower in the 69 included patients $(38 / 69,55 \%)$ than in the 244 patients who were not included $(158 / 244,65 \% ; p=0.09)$.

Sociodemographic and disease characteristics, including physical and mental function, of the 69 included patients are shown in Table 1. In total, 69 patients were recruited from the EAC cohort. Thirty-nine patients (57\%) had definite RA, 8 patients (12\%) had probable RA, 10 (15\%) had psoriatic arthritis, $3(3 \%)$ had spondylarthropathy and 9 (13\%) had unclassified arthritis, with the arthritis still being unclassified after 12 months of follow-up. Twelve of the 39 patients with definite RA also participated in the BeSt study; two were randomized to treatment group 1, three to treatment group 2, five to treatment group 3 and two to treatment group 4.

In total, 6 patients $(9 \%)$ had a symptom duration of $>1$ year, 6 patients $(9 \%)$ had a symptom duration between 6 months and 1 year and 57 patients $(83 \%)$ had a symptom duration of $<6$ months.

Overall, disease activity was moderate, with the median VAS disease activity score being 5.3 (range, $0-10.0$ ) $\mathrm{cm}$, the median ESR 20 (range, 2-105) $\mathrm{mm} / \mathrm{h}$ and the median Ritchie score being $6(0-32)$.
Table 1 Sociodemographic and disease characteristics of 69 patients with early arthritis

\begin{tabular}{ll}
\hline Characteristics & $n(\%)$ \\
\hline Sociodemographic characteristics & \\
Age, in years; median (range) & $42(18-64)$ \\
Female patients, $n$ (\%) & $38(55)$ \\
Living with partner/family, $n$ (\%) & $57(83)$ \\
Educational level, $n$ (\%) & \\
High & $18(26)$ \\
Medium & $32(46)$ \\
Low & $19(28)$ \\
Disease characteristics & \\
Diagnosis, $n$ (\%) & \\
RA (definite) & $39(57)$ \\
RA (probable) & $8(12)$ \\
Psoriatic arthritis & $10(15)$ \\
Arthritis unspecified & $9(13)$ \\
Spondylarthropathy & $3(4)$ \\
Duration of arthritis symptoms, in years; & $0.3(0-2)$ \\
median (range) & \\
VAS, 0-10 cm; median (range) & \\
Disease activity patient & $5.3(0-10.0)$ \\
Pain patient & $4.7(1.0-9.8)$ \\
Fatigue patient & $4.8(0-10.0)$ \\
ESR, in mm/hr; median (range) & $20(2-105)$ \\
Ritchie index (0-68); median (range) & $6(1-32)$ \\
HAQ (0-3); median (range) & $0.63(0-1.88)$ \\
HADS anxiety; median (range) & $5(0-16)$ \\
HADS depression; median (range) & $4(0-13)$ \\
\end{tabular}

Data on the working status are presented in Table 2. Patients were distributed fairly evenly over the four job categories.

At study entry, 22 patients (32\%) were currently on sick leave. In The Netherlands, in the period 2000-2003, the average proportion of persons on sick leave in the working population ranged between 4.8 and $8.4 \%$, depending on the branch (public service or industry) [http://www.cbs.nl]. Twenty-eight patients reported sick leave over the past 12 months, whereas after 12 months follow-up, 18 patients reported sick leave in the preceding period. This difference was mainly accounted for by a decrease in the number of patients reporting sick leave for periods of 1-3 months. In total, 34 patients (49\%) reported sick leave in either 12 months before study entry or 12 months thereafter. Of the 27 patients who reported sick leave due to arthritis in the past 12 months with a specific duration at study entry, 5 were partially or fully work disabled after 12 months of follow up, 10 reported long-term sick leave (1-3 months), 4 reported short-term sick leave (2-4 weeks) and 8 reported no sick leave due to arthritis.

Five patients $(7 \%)$ received a partial disability pension at study entry. In two of these patients, this entitlement was 
Table 2 Working status in 69 patients with early arthritis

\begin{tabular}{llll}
\hline $\begin{array}{l}\text { Study } \\
\text { entry }\end{array}$ & $\begin{array}{l}\text { Follow-up } \\
(12 \text { months })\end{array}$ & $p$ value \\
\hline
\end{tabular}

\begin{tabular}{|c|c|c|c|}
\hline \multicolumn{4}{|l|}{ Job characteristics } \\
\hline \multicolumn{4}{|l|}{$\begin{array}{l}\text { Occupational category, } \\
n(\%)\end{array}$} \\
\hline Mental demands & \multicolumn{3}{|l|}{$18(26)$} \\
\hline $\begin{array}{l}\text { Mixed mental/physical } \\
\text { demands }\end{array}$ & \multicolumn{3}{|l|}{$14(20)$} \\
\hline Light physical demands & \multicolumn{3}{|l|}{$20(29)$} \\
\hline Heavy physical demands & \multicolumn{3}{|l|}{$17(25)$} \\
\hline $\begin{array}{l}\text { Hours of work per week; } \\
\text { median (range) }\end{array}$ & $36(5-70)$ & $34(4-70)^{\mathrm{b}}$ & 0.455 \\
\hline $\begin{array}{l}\text { Full-time employment, } \\
n(\%)\end{array}$ & $34(50)$ & $29(42)$ & 0.375 \\
\hline \multicolumn{4}{|l|}{ Sick leave } \\
\hline Current sick leave, $n(\%)$ & $22(32)$ & & \\
\hline $\begin{array}{l}\text { Sick leave for the past } \\
12 \text { months, } n(\%)\end{array}$ & $28(41)$ & $18(26)$ & 0.031 \\
\hline \multicolumn{4}{|l|}{$\begin{array}{l}\text { Extent of sick leave, } \\
n(\%)\end{array}$} \\
\hline Complete sick leave & $15(54)$ & $12(67)$ & \\
\hline Partial sick leave & $7(25)$ & $3(17)$ & \\
\hline Unknown & $6(21)$ & $3(17)$ & \\
\hline \multicolumn{4}{|l|}{$\begin{array}{l}\text { Duration of sick leave for } \\
\text { the past } 12 \text { months, } n(\%)\end{array}$} \\
\hline 2-4 weeks & $5(18)$ & $7(41)$ & 0.754 \\
\hline $1-3$ months & $14(50)$ & $2(12)$ & 0.002 \\
\hline 3-12 months & $8(29)$ & $8(44)$ & 1.0 \\
\hline Unknown & $1(4)$ & $1(4)$ & 1.0 \\
\hline \multicolumn{4}{|l|}{ Work disability } \\
\hline \multicolumn{4}{|l|}{ Work disability pension } \\
\hline $\begin{array}{l}\text { Complete or partial, } \\
n(\%)\end{array}$ & $5(7)$ & $13(19)$ & 0.008 \\
\hline Complete, $n(\%)$ & 0 & $3(4)$ & 0.250 \\
\hline Partial, $n(\%)$ & $5(7)$ & $10(15)$ & 0.180 \\
\hline
\end{tabular}

${ }^{a} p$ value of Wilcoxon signed rank test or McNemar where appropriate. ${ }^{b}$ Only patients who did not start to receive a work disability pension or an extension of a work disability pension were considered.

extended to a full work disability pension after 12 months, whereas in the other three patients, the disability pension remained unchanged. In addition, eight patients (12\%) started receiving a work disability pension in the 12-month follow-up period (one patient a full disability pension and seven a partial disability pension).

In The Netherlands, the average proportion of employees in the working age range (15-64 years) becoming work disabled over a period of 1 year ranged between 1 and $1.1 \%$ in the period the study was conducted (http://www.cbs.nl). None of the patients became unemployed during follow-up.

A repetition of the analyses excluding the six patients with a symptom duration of $>1$ year showed similar results (data no shown).

Table 3 shows sociodemographic, disease and job characteristics of patients in whom the work status deteriorated (institution or extension of work disability pension) and of patients in whom the working situation improved or remained stable. In the patients in whom the work status deteriorated, the proportions of patients with a diagnosis of definite RA, the occurrence of sick leave in the previous 12 months and a duration of sick leave $>4$ weeks were significantly higher than in the group of patients in whom the working status remained stable. Moreover, patients in whom the working status deteriorated had a significantly higher VAS disease activity compared to patients in whom the working status remained stable or improved.

In the multivariate logistic regression analysis, the occurrence of sick leave in 12 months before study entry was found to be the only significant predictor of deterioration of the working situation (odds ratio, 16.1; 95\%CI, 1.8-142.8).

The presence of material and immaterial adaptations at the workplace is shown in Table 4. The number of patients in whom the workplace was adapted increased from 20 $(29 \%)$ at baseline to 28 patients (42\%) after 1 year followup. The numbers of patients using adapted tools or furniture, flexible time-management or performing different tasks increased significantly with time. Moreover, the average number of workplace adaptations per patient increased significantly.

Table 5 shows the guidance of other persons with the aim of the maintenance of the paid job. At study entry, 48 patients $(70 \%)$ and, in the follow-up period, 36 patients (52\%) received professional guidance, with the rheumatologist, general practitioner and physical therapist being the most frequently mentioned health care professionals. The proportions of patients being satisfied with the guidance were the lowest for the occupational physician. Employers and/or colleagues provided help in one third of patients, for the large majority of patients to their satisfaction.

Thirteen patients $(19 \%)$ would have liked to have more guidance with problems at work, especially from their rheumatologist, a nurse specialized in rheumatology or from their employer.

\section{Discussion}

This study in patients with early chronic arthritis shows that about half of the patients reported arthritis-related sick leave, and $19 \%$ became permanently work disabled over a period 1 year before and 1 year after entering an EAC cohort. Partial work disability was more common than full work disability, and sick leave appeared to be its most important predictor. In addition, work place adaptations, professional guidance and help from employer and/or colleagues were common in this population. 
Table 3 Deterioration of working status ${ }^{\mathrm{a}}$ in 12 months follow up in 69 patients with early arthritis

\begin{tabular}{|c|c|c|c|}
\hline & $\begin{array}{l}\text { More work disability, } \\
n=10\end{array}$ & $\begin{array}{l}\text { Stable work (dis)ability } \\
n=59\end{array}$ & $p$ value $^{\mathrm{b}}$ \\
\hline \multicolumn{4}{|l|}{ Sociodemographic characteristics } \\
\hline Age, years; median (range) & $42(28-58)$ & $44(18-64)$ & 0.484 \\
\hline Female patients, $n(\%)$ & $5(50)$ & $33(56)$ & 0.996 \\
\hline \multicolumn{4}{|l|}{ Educational level, $n(\%)$} \\
\hline High & $5(50)$ & $13(22)$ & 0.141 \\
\hline Medium & $3(30)$ & $29(49)$ & 0.435 \\
\hline Low & $2(20)$ & $17(29)$ & 0.846 \\
\hline \multicolumn{4}{|l|}{ Disease characteristics } \\
\hline \multicolumn{4}{|l|}{ Diagnosis, $n(\%)$} \\
\hline RA (definite) & $9(90)$ & $30(51)$ & 0.049 \\
\hline RA (probable) & 0 & $8(14)$ & 0.481 \\
\hline Arthritis unspecified & $1(10)$ & $8(14)$ & 1.0 \\
\hline Psoriatic arthritis & 0 & $10(17)$ & 0.356 \\
\hline Spondylarthropathy & 0 & $3(5)$ & 1.0 \\
\hline Duration of symptoms, years; median (range) & $0.4(0-0.9)$ & $0.3(0-2)$ & 0.955 \\
\hline \multicolumn{4}{|l|}{ VAS, $0-10 \mathrm{~cm}$; median (range) } \\
\hline Disease activity patient & $7.5(4.1-9.8)$ & $5.1(0-10.0)$ & 0.038 \\
\hline Pain patient & $5.7(2.1-9.8)$ & $4.6(1.0-9.6)$ & 0.096 \\
\hline Fatigue patient & $5.9(5.0-9.8)$ & $4.0(0-10.0)$ & 0.131 \\
\hline \multicolumn{4}{|l|}{ Disease activity } \\
\hline ESR, mm/h; median (range) & $26(6-105)$ & $17(2-93)$ & 0.264 \\
\hline Ritchie index (0-68); median (range) & $14(2-17)$ & $6(1-32)$ & 0.068 \\
\hline \multicolumn{4}{|l|}{ Physical and mental functioning } \\
\hline HAQ (0-3); median (range) & $0.88(0-1.75)$ & $0.63(0-1.88)$ & 0.174 \\
\hline HADS anxiety; median (range) & $6.5(0-13)$ & $5(0-16)$ & 0.650 \\
\hline HADS depression; median (range) & $5(1-13)$ & $3(0-11)$ & 0.195 \\
\hline \multicolumn{4}{|l|}{ Job characteristics } \\
\hline \multicolumn{4}{|l|}{ Current occupational category, $n(\%)$} \\
\hline Mental demands & $3(30)$ & $15(25)$ & 1.0 \\
\hline Mixed mental/physical demands & $3(30)$ & $11(19)$ & 0.689 \\
\hline Light physical demands & $1(10)$ & $19(32)$ & 0.292 \\
\hline Heavy physical demands & $3(30)$ & $14(24)$ & 0.977 \\
\hline Sick leave related to arthritis 12 months before study entry, $n(\%)$ & $9(90)$ & $19(32)$ & 0.002 \\
\hline \multicolumn{4}{|c|}{ Duration of sick leave related to arthritis in 12 months before study entry, $n(\%)$} \\
\hline $2-4$ weeks & 0 & $5(26)$ & 0.767 \\
\hline $1-3$ months & $5(56)$ & $9(47)$ & 0.036 \\
\hline $3-12$ months & $4(44)$ & $5(26)$ & 0.026 \\
\hline
\end{tabular}

${ }^{\text {a }}$ Deterioration of work status defined as starting to receive a work disability pension or altering from a partial to a full work disability pension after 12 months of follow-up.

${ }^{\mathrm{b}} p$ value of Mann-Whitney $U$ test or chi-square where appropriate

With respect to the occurrence of sick leave, our results are in accordance with those of previous follow-up studies in patients with early arthritis, where sick leave rates of 50 $60 \%$ over a period of 1 year were reported [7, 14, 15]. As in our study, $83 \%$ of the patients had a disease duration of less than 6 months; our data on the occurrence of sick leave in the 12 months before study entry suggest that in a considerable proportion of patients, sick leave may occur before they enter an EAC, and a diagnosis of arthritis has been made. In our study, the occurrence of sick leave decreased with time, a finding that cannot be completely interpreted as a positive observation, as it was in part explained by patients on sick leave becoming permanently work disabled (Table 6).

In our study, $19 \%$ of the patients were permanently work disabled after 2 years of follow-up. This figure is in the same range or somewhat more favourable than work disability rates found in previous studies in patients with early RA [7-9]. In fact, our results may even be more favourable, as work disability was partial in the majority of patients, whereas in other studies, only complete job loss was considered. It should be noted, however, that our study 
Table 4 Presence of material and immaterial adaptations at the workplace in 69 patients with early arthritis

\begin{tabular}{|c|c|c|c|}
\hline & $\begin{array}{l}\text { Study } \\
\text { entry, } \\
n=69\end{array}$ & $\begin{array}{l}\text { Follow-up } \\
\text { (12 months), } \\
n=66\end{array}$ & $p$ value $^{\mathrm{a}}$ \\
\hline $\begin{array}{l}\text { No. of patients with } \\
\text { adaptations, } n(\%)\end{array}$ & $20(29)$ & $28(42)$ & 0.134 \\
\hline $\begin{array}{l}\text { No. of adaptations per } \\
\text { person }^{\text {b }} \text { median (range) }\end{array}$ & $\begin{array}{l}2.5 \\
(1-6)\end{array}$ & $3.0(1-9)$ & $<0.001$ \\
\hline \multicolumn{4}{|l|}{ Types of adaptations } \\
\hline $\begin{array}{l}\text { Adapted tools/furniture, } \\
n(\%)\end{array}$ & $1(3)$ & $11(17)$ & 0.002 \\
\hline $\begin{array}{l}\text { Different tasks (extra } \\
\text { education), } n(\%)\end{array}$ & $2(3)$ & $12(18)$ & 0.013 \\
\hline $\begin{array}{l}\text { Reduction of tasks/duties, } \\
n(\%)\end{array}$ & $9(13)$ & $18(27)$ & 0.064 \\
\hline Help of colleagues, $n(\%)$ & $9(13)$ & $15(23)$ & 0.210 \\
\hline $\begin{array}{l}\text { Flexible working hours, } \\
n(\%)\end{array}$ & $10(15)$ & $7(11)$ & 0.581 \\
\hline $\begin{array}{l}\text { Flexible time-management, } \\
n(\%)\end{array}$ & $7(10)$ & $17(26)$ & 0.021 \\
\hline Less working hours, $n(\%)$ & $8(12)$ & $12(18)$ & 0.424 \\
\hline Reduced work pace, $n(\%)$ & $5(7)$ & $7(11)$ & 0.774 \\
\hline
\end{tabular}

${ }^{a} p$ value of McNemar test or Wilcoxon signed rank test where appropriate.

${ }^{\mathrm{b}}$ Only considering patients with one or more adaptations.

concerned various forms of chronic arthritis, and a deterioration of the working situation appeared to be more frequent among patients with a diagnosis of definite RA than in patients with other forms of arthritis. Our results are in concordance with the observation that the incidence of permanent work disability among RA and AS patients appears to be declining over the last decades, most probably related to new developments in pharmacological therapy [23-25]. Indeed, the patients included in our study were promptly treated, with the medical treatment for the patients with RA consisting of either monotherapy with methotrexate or salazopyrine or treatment according to the $\mathrm{BeSt}$ protocol [17].

In this study, the duration of symptoms varied among patients, so that not all patients were at equal risk of developing sick leave or work disability. The impact of the symptom duration may however be limited, as one of our analyses showed that symptom duration had no effect on the development of more work disability in the follow-up period of 12 months.

In this study, no control group was used for comparison. Data from the Dutch Central Bureau of Statistics (http:// www.cbs.nl) indicate that there is a considerable "background risk" of sick leave and work disability in the general population. However, as in this study, patients were explicitly asked to report sick leave and work disability due to arthritis; it is doubtful whether this background risk needs to be taken into account. It appeared that sick leave and work disability rates among patients with early arthritis were considerably higher than those in the general population; however, for valid comparisons, a separate study with similar registration methods among patients with early arthritis and the general population is needed.

With respect to the determinants of work disability, similar to studies in RA [26], disease severity was, in general higher, and physical and psychological functioning worse among patients in whom the working status deteriorated than in those in whom the working status remained stable. The fact that the association of some measures of disease severity or physical or psychological functioning with changes in the working status did not reach statistical significance may have been due to the relatively small sample size of this study. Moreover, our finding that the occurrence of sick leave in the 12 months before study entry was associated with a deterioration of the working situation is in concordance with the results of another study by our group among another group of patients with various form of chronic arthritis [27]. The results of both studies underscore the importance of the recognition of sick leave as a risk factor for work disability in patients with chronic arthritis. Previously, it has been questioned whether rheumatologists do sufficiently recog-

Table 5 Usage of and satisfaction with professional guidance and help of employers/colleagues with respect to arthritis-related problems at work in 69 patients with early arthritis

\begin{tabular}{|c|c|c|c|c|}
\hline & \multicolumn{2}{|c|}{ Study entry } & \multicolumn{2}{|c|}{ Follow-up (12 months) } \\
\hline & Usage & Satisfaction & Usage & Satisfaction \\
\hline $\begin{array}{l}\text { Rheumatologist, } \\
n(\%)\end{array}$ & $37(54)$ & $35(95)$ & $21(30)$ & $21(100)$ \\
\hline $\begin{array}{l}\text { General } \\
\text { practitioner, } \\
n(\%)\end{array}$ & $34(49)$ & $29(85)$ & $12(17)$ & $12(100)$ \\
\hline $\begin{array}{l}\text { Physiotherapist, } \\
n(\%)\end{array}$ & $24(35)$ & $20(83)$ & $21(30)$ & $21(100)$ \\
\hline $\begin{array}{l}\text { Occupational } \\
\text { physician, } \\
n(\%)\end{array}$ & $16(23)$ & $12(75)$ & $19(28)$ & $13(68)$ \\
\hline $\begin{array}{l}\text { Social worker, } \\
n(\%)\end{array}$ & $6(9)$ & $6(100)$ & $4(6)$ & $4(100)$ \\
\hline $\begin{array}{l}\text { Clinical nurse } \\
\text { specialist, } \\
n(\%)\end{array}$ & $6(9)$ & $6(100)$ & $9(13)$ & $8(89)$ \\
\hline $\begin{array}{l}\text { Occupational } \\
\text { therapist, } n(\%)\end{array}$ & $5(7)$ & $5(100)$ & $9(13)$ & $8(89)$ \\
\hline Total & $48(70)$ & & $41(59)$ & \\
\hline $\begin{array}{l}\text { Employer/ } \\
\text { colleagues, } \\
n(\%)\end{array}$ & $23(33)$ & $21(91)$ & $21(30)$ & $19(91)$ \\
\hline
\end{tabular}

All values expressed as numbers (\%) 
Table 6 Working situation after 12 months of follow-up in 27 patients with early arthritis who reported sick leave at study entry (in one patient the duration of sick leave was unknown)

\begin{tabular}{|c|c|c|c|c|c|c|}
\hline \multirow{2}{*}{$\begin{array}{l}\text { Study entry } \\
\text { Duration of sick } \\
\text { leave }\end{array}$} & \multicolumn{6}{|l|}{ Follow-up } \\
\hline & $\begin{array}{l}\text { Partial work } \\
\text { disability }\end{array}$ & $\begin{array}{l}\text { Full work } \\
\text { disability }\end{array}$ & $\begin{array}{l}\text { Sick leave } \\
2-4 \text { weeks }\end{array}$ & $\begin{array}{l}\text { Sick leave } \\
1-3 \text { months }\end{array}$ & $\begin{array}{l}\text { Sick leave } \\
3-12 \text { months }\end{array}$ & $\begin{array}{l}\text { No sick } \\
\text { leave }\end{array}$ \\
\hline $2-4$ weeks $(n=5)$ & 0 & 0 & 1 & 2 & 0 & 2 \\
\hline $1-3$ months $(n=14)$ & 2 & 1 & 3 & 1 & 3 & 4 \\
\hline $3-12$ months $(n=8)$ & 1 & 1 & 0 & 0 & 4 & 2 \\
\hline
\end{tabular}

nize patients' working problems [28] of which sick leave could be considered as one of its manifestations. Apart from paying attention to the presence of sick leave, the use of instruments that have been specifically developed for the identification of those individuals with chronic arthritis having difficulties at work could be helpful because by using these tools, working problems could be recognized in earlier stages. Examples of those instruments are the RAWork Instability Scale [29] and the Work Limitations Questionnaire [30]. In addition, Detaille et al. [31] showed which issues are important from the patients' perspective and recommended a topic list for various health professionals to use during consultations. So far, these instruments are only partly validated, have been mainly used in studies, and are not developed to be applied at the individual level. At present, valid and brief questionnaires specifically designed for clinical practice are not yet available. It is however conceivable that simply asking patients about working problems or sick leave is another sensitive method to identify patients at risk of work disability.

The results of this study show that over a period of 2 years, in $30-40 \%$ of the patients, the work situation was adapted, about $30 \%$ received help from the employer or colleagues and $60-70 \%$ of patients received professional guidance to maintain their job. With respect to the implementation of work place adaptations and help from the employer or colleagues, these figures are in line with those of a recent study in early RA patients [32]. In that study, it was demonstrated that support and help of coworkers, employer help, shortened work days, new skills and a modified work station or equipment were among the work-related factors that significantly ameliorated work ability. With respect to professional guidance, a recent study in Dutch employing RA patients with a short disease duration found that according to the patients, the mobilization of health care professionals would help them tackle their threats to work ability [33].

In our study, patients were generally very appreciative of help concerning their working problems, with the lowest proportions of patients being satisfied obtained for the occupational physician. In The Netherlands, the importance of the role of occupational physician in the maintenance of a paid job in patients with chronic diseases is generally recognized. However, in a previous study, the communication between occupational physicians and rheumatologists was found to be hampered [34], factor that could have contributed to the relatively low satisfaction scores.

A limitation of the present study may be that the total number of patients was relatively low, and various types of chronic arthritis were included, hampering conclusions about specific diagnosis groups. Moreover, in this study, about $25 \%$ of all patients in the working age range $(<65$ years) who entered the EAC participated in the work disability study. This proportion is significantly lower than the percentages of patients with a paid job at symptom onset in similar age groups in early RA cohorts, with frequencies ranging between 50 and $75 \%$ [11, 35-37]. As the sociodemographic and clinical characteristics of the non-participants were not systematically gathered, it remains unclear to what extent the population included in this study differs from all patients with early arthritis who have a paid job at symptom onset. Given the probability of selection bias, our results have to be interpreted with care.

In conclusion, this study in patients with early chronic arthritis and a paid job showed that the occurrence of arthritis-related sick leave, before and directly after a diagnosis is made, is substantial. In contrast, full permanent work disability developed in a relatively small minority. Work place adaptations, professional guidance and help from employers or colleagues to maintain a paid job were fairly common. Future research should aim at the detection of patients at risk for the development of sick leave and permanent work disability, as well as the optimization of the process of vocational guidance.

Acknowledgements This study was financially supported by a grant from the Dutch Medical Science Organisation (NWO), grant no. 94036-009. We are indebted to Mrs. N. Olsthoorn, research nurse, for assistance with patient recruitment, data collection and data entry, and to S. van der Kooy and K. Verpoort, Ph.D. students, for providing additional data on the EAC cohort and BeSt study. 


\section{References}

1. Verstappen SMM, Bijlsma JWJ, Verkleij H, Buskens E, Blaauw AAM, ter Borg EJ, Jacobs JW (2004) Overview of work disability in rheumatoid arthritis patients as observed in cross-sectional and longitudinal surveys. Arthritis Rheum 51:488-497

2. Boonen A, Chorus A, Miedema H, van der Heijde D, Landewe R, Schouten H, van der Tempel H, van der Linden S (2001) Withdrawal from the labour force due to work disability in patients with ankylosing spondylitis. Ann Rheum Dis 60:1033-1039

3. Partridge AJ, Karlson EW, Daltroy LH, Lew RA, Wright EA, Fossel AH et al (1997) Risk factors for early work disability in systemic lupus erythematosus. Arthritis Rheum 40:2199-2206

4. Huscher D, Merkesdal S, Thiele K, Zeidler H, Schneider M, Zink A (2006) Cost of illness in rheumatoid arthritis, ankylosing spondylitis, psoriatic arthritis and SLE in Germany. Ann Rheum Dis 65:1175-1183

5. Mau W, Listing J, Huscher D, Zeidler H, Zink A (2005) Employment across chronic inflammatory rheumatic diseases and comparison with the general population. J Rheumatol 32:721-728

6. Sokka T (2003) Work disability in early arthritis. Clin Exp Rheumatol 21(Suppl 31):S71-S74

7. Newhall-Perry K, Law NJ, Ramos B, Sterz M, Wong WK, Bulpitt KJ, Park G, Lee M, Clements P, Paulus HE (2000) Direct and indirect costs associated with the onset of seropositive rheumatoid arthritis. J Rheumatol 27:1156-1163

8. Jäntti J, Aho K, Kareela K, Kautiainen H (1999) Work disability in an inception cohort of patients with seropositive rheumatoid arthritis: a 20 year study. Rheumatology 38:1138-1141

9. Barrett EM, Scott DGI, Wiles NJ, Symmons DPM (2000) The impact of rheumatoid arthritis on employment status in the early years of disease: a UK community-based study. Rheumatology 39:1403-1409

10. Backman CL (2004) Employment and work disability in rheumatoid arthritis. Curr Opin Rheumatol 16:148-152

11. Doeglas D, Suurmeijer T, Krol B, Sanderman R, van Leeuwen M, van Rijswijk M (1995) Work disability in early rheumatoid arthritis. Ann Rheum Dis 54:455-460

12. Mau W, Bornmann M, Weber H (1996) Indikatoren der Arbeitsunfähigkeit im ersten jahr der chronischen polyarthritis [Indicators of sick-leave in the first year of rheumatoid arthritis]. Z Rheumatol 55:233-240

13. Mau W, Bornmann M, Weber H (1997) Arbeitsunfähigkeit im ersten Jahr der chronischen polyarthritis. Ein Vergleich mit Pflichtmitgliedern der gesetzlichen Krankenversicherung. [The occurrence if sick-leave in the first year of rheumatoid arthritis. A comparison with the members of the compulsory health insurance]. Z Rheumatol 56:1-7

14. Hallert E, Husberg M, Jonsson D, Skogh T (2004) Rheumatoid arthritis is already expensive during the first year of the disease (the Swedish TIRA project). Rheumatology 43:1374-1382

15. Westhoff G, Weber C, Zink A (2002) Job features, disease activity and sick leave days in patients with rheumatoid arthritis. Arthritis Rheum 46(Suppl):S460-S460

16. Van Aken J, Van Bilsen JH, Allaart CF, Huizinga TW, Breedveld FC (2003) The Leiden Arthritis Clinic. Clin Exp Rheumatol 21(Suppl 31): S100-S105

17. Goekoop-Ruiterman YP, de Vries-Bouwstra JK, Allaart CF, van Zeben D, Kerstens PJ, Hazes JM, Zwinderman AH, Ronday HK, Han KH, Westedt ML, Gerards AH, van Groenendael JH, Lems WF, van Krugten MV, Breedveld FC, Dijkmans BA (2005) Clinical and radiographic outcomes of four different treatment strategies in patients with early rheumatoid arthritis (the BeSt-study): a randomized, controlled trial. Arthritis Rheum 52:3381-3390

18. Arnett FC, Edworth SM, Bloch DA, McShane DJ, Fries JF, Cooper NS, Healey LA, Kaplan SR, Liang MH, Luthra HS (1988) The American Rheumatism Association 1987 revised criteria for the classification of rheumatoid arthritis. Arthritis Rheumatism 31:315-324
19. Ritchie DM, Boyle JA, McInnes JM, Jasani MK, Dalakos TG, Grieveson P, Buchanan WW (1968) Clinical studies with an artricular index for the assessment of joint tenderness in patients with rheumatoid arthritis. Q J Med 37:393-406

20. Siegert CE, Vleming L-J, Vandenbroucke JP, Cats A (1984) Measurement of disability in Dutch rheumatoid artritis patients. Clin Rheumatol 3:305-309

21. Spinhoven P, Ormel J, Sloekers PP, Kempen GI, Speckens AE, van Hemert AM (1997) A validation study of the Hospital Anxiety and Depression Scale (HADS) in different groups of Dutch subjects. Psychol Med 27:363-370

22. De Zwart BC, Broersen JP, van der Beek AJ, Frings-Dresen MH, van Dijk FJ (1997) Occupational classification according to work demands: an evaluation study. Int J Occup Med Environ Health 10:283-295

23. Yelin E, Trupin L, Katz P, Lubeck D, Rush S, Wanke L (2003) Association between etanercept use and employment outcomes among patients with rheumatoid arthritis. Arthritis Rheum 48:3046-3054

24. Puolakka K, Kautiainen H, Möttönen T, Hannonen P, Korpela M, Julkunen H, Luukkainen R, Vuori K, Paimela L, Blafield H, Hakala M, Leirisalo-Repo M (2004) Impact of initial aggressive drug treatment with a combination of disease modifying antirheumatic drugs on the development of work disability in early rheumatoid arthritis. Arthritis Rheum 50:55-62

25. Listing J, Brandt J, Rudwaleit M, Zink A, Sieper J, Braun J (2004) Impact of anti-tumour necrosis factor $\alpha$ treatment on admissions to hospital and days of sick leave in patients with ankylosing spondylitis. Ann Rheum Dis 63:1670-1672

26. De Croon EM, Sluiter JK, Nijssen TF, Dijkmans BAC, Lankhorst GJ, Frings-Dresen MHW (2004) Predictive factors of work disability in rheumatoid arthritis: a systematic literature review. Ann Rheum Dis 63:1362-1367

27. De Buck PDM, de Bock GH, van Dijk FJH, Vandenbroucke JP, Vliet Vlieland TPM (2006) Sick leave as a predictor of job loss in patients with chronic arthritis. Int Arch Occup Environ Health 80:160-170

28. Gilworth G, Haigh R, Tennant A, Chamberlain MA, Harvey AR (2001) Do rheumatologists recognize their patients' work related problems? Rheumatology 40:1206-1210

29. Gilworth G, Chamberlain MA, Harvey A, Woodhouse A, Smith J, Smyth MG, Tennant A (2003) Development of a work instability scale for rheumatoid arthritis. Arthritis Rheum 49:349-354

30. Lerner D, Amick BC, Rogers WH et al (2001) The work limitations questionnaire. Med Care 39:72-85

31. Detaille SI, Haafkens JA, van Dijk FJ (2003) What employees with rheumatoid arthritis, diabetes mellitus and hearing loss need to cope with at work. Scand J Work Environ Health 29:134-142

32. Lacaille D, Sheps S, Spinelli JJ, Chalmers A, Esdaile JM (2004) Identification of modifiable work-related factors that influence the risk of work disability in rheumatoid arthritis. Arthritis Rheum 51:843-852

33. de Croon EM, Sluiter JK, Nijssen TF, Kanmeijer M, Dijkmans BA, Lankhorst GJ, Frings-Dresen MH (2005) Work ability of Dutch employees with rheumatoid arthritis. Scand J Rheumatol 34:277-283

34. de Buck PD, van Amstel RJ, Buijs PC, Maasen JH, van Dijk FJ, Hazes JM, Vliet Vlieland TP (2002) Communication between Dutch rheumatologists and occupational physicians in the occupational rehabilitation of patients with rheumatic diseases. Ann Rheum Dis 61:62-65

35. Van Jaarsveld CHM, Jacobs JWG, Schrijvers AJP, Van AlbadaKuipers GA, Hofman DA, Bijlsma JWJ (1998) Effects of rheumatoid arthritis on employment and social participation during the first years of disease in the Netherlands. Br J Rheumatol 37:848-853

36. Young A, Dixey J, Cox N, Davies P, Devlin J, Emery P et al (2000) How does functional ability in early rheumatoid arthritis (RA) affect patients and their lives? Results of 5 years of follow-up in 732 patients from the Early RA Study (ERAS). Rheumatology 39:603-611

37. Merkesdal S, Ruof J, Huelsemann JL, Mittendorf T, Handelmann S, Mau W, Zeidler H (2005) Arthritis Rheum 53:234-240 